\title{
DA EDUCAÇÃO PRIMÁRIA AO ENSINO SUPERIOR: O DESAFIO DAS MULHERES DE COR E TRABALHADORAS PARA ALCANÇAR A EDUCAÇÃO ESCOLAR NO BRASIL ENTRE O FINAL DO SÉCULO XIX E INÍCIO DO SÉCULO XX*
}

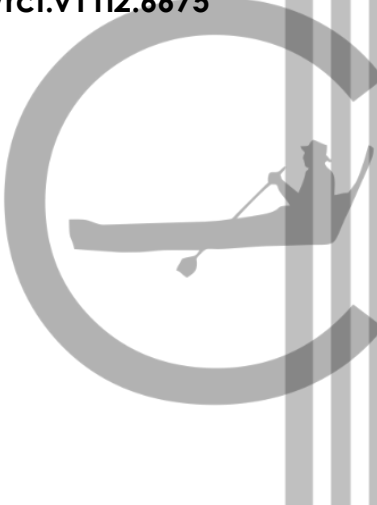

\author{
Jucimar Cerqueira dos Santos 1 \\ Mayara Priscilla de Jesus dos Santos²
}

\section{Resumo}

Esse texto tem o objetivo de discutir proposições e iniciativas de escolarização para mulheres trabalhadoras e de cor, entre o final do século XIX e início do século XX, partindo de algumas experiências de escolarização na Bahia e do caso de Maria Odília Teixeira, a primeira mulher negra a se formar na FAMEB (Faculdade de Medicina da Bahia) em 1909. As fontes para o texto são ofícios do setor de Instrução Pública da Bahia, relatório de inspetores literários da Bahia, teses doutorais e memórias históricas da Biblioteca Gonçalo Moniz, matrículas, pagamentos e atestados do Arquivo da Faculdade de Medicina da Bahia, jornais e fonte oral. O período historiográfico em tela é de considerável relevância para compreender o processo de declínio da escravidão no Brasil, do advento da República e do pós-abolição. Tais fatores estiveram evidentes não somente a partir da promulgação de lei de 13 de maio de 1888, mas como reflexo das ações de homens e mulheres que contestaram a ordem escravista de forma também a enfraquecê-la até o decreto da lei e a escolarização se apresenta como uma das vias de resistência e mudanças na vida dessas pessoas.

Palavras chaves: Educação; Mulheres negras; Pós abolição.

\begin{abstract}
This text aims to discuss schooling proposals and initiatives for working and colored women, between the end of the 19th century and the beginning of the 20th century, starting from some schooling experiences in Bahia and the case de Maria Odília Teixeira, the first woman to graduate from FAMEB (Faculdade de Medicina da Bahia) in 1909. The sources for the text are trades from the Bahia Public Instruction sector, report byliteraty inspectores from Bahia, doctoral theses and historical memories from the Gonçalo Moniz Library, enrollments, payments and certificates from the Bahia Medical School Archive, newspapers and oral source. The historiographic period on screen is of considerable relevance for understanding the processo $d$ declining slavery in Brazil, the advento $f$ the Republic and the pos-abolition period. Suche factors were evidente not only after the enactment of the law of May 13,1888, but as a reflection of the actions of men and women who challenged the slave order in order to weaken it until the decree of the law and schooling appears as one of the ways of resistance and changes in the lives of these people.
\end{abstract}

Keywords: Education; black women; Post Abolition.

\footnotetext{
${ }^{1}$ Doutorando e Mestre em História Social pela Universidade Federal da Bahia.

${ }^{2}$ Mestre pela Universidade Federal da Bahia.
} 
A escolarização de mulheres trabalhadoras e de cor é uma questão importante para ser discutida, pois no Brasil, desde a implantação do sistema escravista, elas foram relegadas a uma posição social inferior a de outras mulheres, a de homens e até mesmo negros. Posição essa que necessitava de pouco ou nenhum letramento para sobrevivência, ao serem direcionadas ao trabalho de cativeiro (no tempo da escravidão sistêmica), de criada, à condição de mãe ou de trabalhadora nas ruas como comerciantes ou prestadoras de serviços como lavadeiras e moças de recados em parte dos casos da história brasileira. ${ }^{3}$ Havia casos em que estudavam também a serviço do trabalho escravo, como na condição de ganho, como aponta João José Reis ao analisar documentos sobre grupos de homens e mulheres negras, escravizadas, livres e libertas, que em centros urbanos vendiam produtos, muitos deles de alimentação, em lugares chamados cantos. Algumas dessas pessoas eram escravizadas e muitas delas sabiam ler, escrever e contar. ${ }^{4}$ Algumas tinham as três habilidades, duas ou uma delas para poderem exercer tal ofício, que no caso da condição de cativeiro, permitia certa autonomia em relação a seus senhores, pois poderiam morar em cidades diferentes, e recebiam uma fração do lucro desse tipo de comércio, o que possibilitava acumular dinheiro para pagamento de alforria, que poderia significar liberdade, emancipação e até mesmo a possibilidade de alcançar outros lugares sociais.

Pautar a história da educação escolar para essas mulheres nesse período é refletir o quanto ela foi e é significativa, mesmo em quantidade pequena e, em algumas vezes, estando a serviço de senhores e patrões. Mulheres negras são referência de resistência e enfrentamento de estigmas como o machismo e o racismo, sendo de extrema utilidade para as gerações posteriores poderem prosseguir nos enfrentamentos e ampliarem as possibilidades e os níveis de escolarização a serem alcançados. Discutir textualmente algumas proposições e casos de escolarização para elas é algo ainda mais instigante em uma sociedade construída com profundas desvantagens, desde o sequestro em África até os dias atuais. Portanto, o objetivo desse texto é discutir formas possíveis de educação escolar para mulheres negras no Brasil a partir de uma documentação sobre a Bahia, e em diálogo com uma bibliografia sobre outros lugares do país. O recorte temporal escolhido para esta análise busca provocar um "olhar" sobre como essas mulheres tiveram acesso a

\footnotetext{
${ }^{3}$ CARNEIRO, Maria Elizabeth Ribeiro. Procura-se "preta, como muito bom leite, prendada e carinhosa": uma cartografia das amas-de-leite na sociedade carioca (1850-1888). Tese de doutorado defendida no Programa de Pós-Graduação em História da Universidade de Brasília, Brasília, 2006.

${ }^{4}$ REIS, João José. Ganhadores: a greve negra de 1857 na Bahia. São Paulo: Companhia das letras, 2019.
} 
escolas. É importante balizar que os movimentos abolicionistas partiram de frentes distintas, entre elas, havia a perspectiva de pessoas que viviam, ou tinham vivido, a condição de escravidão e havia a de grupos que almejavam o fim da escravidão pelo "atraso" que ela significava para um país que se pretendia "moderno", "civilizado", industrializado" e "branco", de acordo com grupos hegemônicos da época5.

Nesse tempo, algumas medidas foram voltadas para essa escolarização. Tais medidas apresentam traços que se mostram conectados a esse contexto emancipacionista, como discutido em Tornando-se livres: Agentes históricos e lutas sociais no processo de abolição, organizado por Maria Helena Machado e Celso Thomas Castilho. ${ }^{6}$ Analisar casos na Bahia propõe pensar a educação escolar de mulheres no Brasil em um período em que não era comum que a instrução ampla fosse destinada ao sexo feminino, muitos menos a escravizadas e libertas. Ao ampliarmos o cenário para o Brasil, em outro nível educacional, através de uma trajetória singular, podemos entender como se deu o processo de lutas, individuais ou coletivas, para que as mulheres tivessem acesso ao ensino superior no país.

\section{Formação Feminina Popular: As Escolas Noturnas na Bahia}

A escolarização noturna foi um acontecimento em várias províncias brasileiras no final do século XIX, principalmente nas décadas de 70 e 80, quando as agitações abolicionistas foram mais intensas. Tal relação é feita pela maioria dos trabalhos que analisa a constituição dessas escolas, consideradas decorrentes de uma escolarização abolicionista. ${ }^{7}$ Elas foram criadas em quantidade considerável e muitas resultaram de iniciativas dos governos provinciais, de professores particulares e também de instituições, como organizações de trabalhadores, com a colaboração do governo ou de maneira

\footnotetext{
${ }^{5}$ ALBUQUERQUE, Wlamyra Ribeiro de. O Jogo da dissimulação: abolição e cidadania negra no Brasil. São Paulo: Companhia das Letras, 2009.

${ }^{6}$ MACHADO, Maria Helena Pereira Toledo; CASTILHO, Celso Thomas. Tornando-se livres: Agentes históricos e lutas sociais no processo de abolição. São Paulo: EDUSP, 2015.

${ }^{7}$ GONDRA, José; SCHUELER, Alessandra. Educação, Poder e Sociedade no Império Brasileiro. São Paulo: Cortez, 2008; LOPES, Katia Geni Cordeiro. A presença de negros em espaços de instrução elementar da cidade-corte: O caso da Escola da Imperial Quinta da Boa Vista. Dissertação de mestrado, Programa de Pós-Graduação em Políticas Públicas, Universidade do Estado do Rio de Janeiro, 2012; LUZ, Itacir Marques da. Compassos letrados: Profissionais negros entre instrução e ofício no Recife (18401860). Dissertação de mestrado - Programa de Pós-Graduação em Educação, UFPB, 2008; MAC CORD, Marcelo. Artífices da cidadania: mutualismo, educação e trabalho no recife oitocentista. Campinas, SP: Ed Unicamp, 2012; MAC CORD, Marcelo; ARAÚJO, Carlos Moreira de; GOMES, Flávio dos Santos (orgs). Rascunhos Cativos: educação, escolas e ensino no Brasil escravista. Rio de Janeiro: 7 Letras/Faperj, 2017 e SANTOS, Jucimar Cerqueira dos. Escolas noturnas para trabalhadores na Bahia (1870-1889). Dissertação de Mestrado pelo Programa de Pós-Graduação em História Social da Faculdade de Filosofia e Ciências Humanas, Universidade Federal da Bahia, Salvador, 2017.
} 
autônoma. Essas escolas foram criadas quando houve mudanças significativas no cenário político, econômico e social do país, no momento em que findava a guerra contra o Paraguai (1864-1870); o movimento republicano estava em ascensão; proliferavam os debates sobre as leis emancipacionistas; e a produção cafeeira estava em desenvolvimento no vale do Paraíba e no Oeste paulista. Nesta época, a consolidação da nação também ganhava mais vigor com base em princípios como "progresso", "modernização", "desenvolvimento" e "civilização" - inspirados em projetos políticos de países como Inglaterra e Estados Unidos. Ressalta-se que o nível de ensino para tais escolas era o de primeiras letras, também chamado de ensino elementar, básico ou primário: a aprendizagem de cálculos básicos e a doutrina cristã católica apostólica romana. Era previsto que essas escolas fossem regidas pelo princípio da liberdade de ensino, assim como as escolas de primeiras letras diurnas. Esse princípio estava voltado para atuação de professores e previa certa isenção de gastos por parte do governo provincial. Ele determinava que todo cidadão que comprovasse conhecimento no que estava se propondo a ensinar o chamado "notório saber", e que atestasse moralidade compatível com a função, através de carta assinada pelo pároco da freguesia, poderia lecionar sem necessariamente ser formado professor pela escola normal.

É importante salientar que a ideia de escolarização como uma instituição segmentada, organizada com alguns critérios, com um espaço físico e a organização de conteúdos se adequa ao que Dominique Julia chama de "inculcação de determinados conhecimentos". Por sua vez, Justino Magalhães aponta que escolarização é o processo de sistematização da escola como instância educativa. Ao se analisar a documentação sobre História da educação, percebe-se que esses moldes foram muito próximos de como as escolas noturnas se estabeleceram na Bahia em fins do século XIX. ${ }^{8}$

Tendo em perspectiva o aumento do acesso à educação, segundo Vanilda Paiva, ela passou a ser considerada um dos elementos fundamentais para a formação da nação em consolidação, desde as mobilizações políticas em torno da independência do Brasil. Para atender a essa perspectiva, a Instrução Pública foi o setor do governo imperial oficializado a partir do decreto de 1827. Esse setor foi responsável pela direção das escolas diurnas,

\footnotetext{
${ }^{8}$ JULIA, Dominique. A Cultura Escolar como Objeto História. Gizele de Souza (Tradução). Revista Brasileira de História de Educação. n. 1 jan./jun. 2001, p22. Disponível em: http://periodicos.uem.br/ojs/index.php/rbhe/article/view/38749. Acesso em 13 de abril de 2020 e MAGALHÃES, Justino. "Um contributo para a História do processo de escolarização da sociedade portuguesa na transição do Antigo Regime". In: Educação, Sociedade e Culturas, n 5. Porto: Afrontamento, 1996, p32.
} 
das aulas particulares e do nível secundário em cada província. Seu principal responsável era o diretor geral, chefiado pelos presidentes das províncias. O decreto educacional de 1827 estabeleceu critérios para a educação brasileira no século XIX, buscando dividir a responsabilidade da educação entre os poderes públicos e os cidadãos dispostos a lecionar. ${ }^{9}$ Segundo José Carlos de Araújo Silva, a partir desse decreto foram constantes as solicitações para a abertura de escolas em todas as localidades das províncias, que "partiram das autoridades religiosas, das Câmaras Municipais e dos moradores das localidades, estes, intermediados na maioria das vezes pelos padres ou pelos próprios professores". O autor ainda aponta que em escolas particulares houve medidas, primordialmente de caráter filantrópico, dirigidas por particulares e instituições religiosas muito embasadas na liberdade de ensino. ${ }^{10}$

A educação foi uma das principais demandas colocadas em pauta nas discussões políticas do Império em busca da consolidação do Brasil enquanto nação, até mesmo decorrente das estratégias e das formas políticas da época, evidentes em partidos como o Liberal e o Conservador. Era grande o número de pessoas que não sabiam ler nem escrever plenamente, mesmo após algum tempo da independência política do país, depois de decretos educacionais, como o de 1827 , o de 1834 e o de 1854. Esse último dava bastante ênfase na inspeção das aulas em todos os níveis. Segundo Luis Anselmo da Fonseca, professor e entusiasta da agenda abolicionista em pauta, a partir da década de 1870, a ignorância era um dos maiores males do Brasil no século XIX, "combatê-la, dissipá-la, tirar o povo do estado de atraso em que ele se achava, dar-lhe educação para aprender uma profissão era uma das missões de maior patriotismo a que as circunstâncias sociais se podiam dedicar". A educação na segunda metade do século XIX tem tamanha importância que existe uma bibliografia que a interliga às propostas abolicionistas nesse período. Sobre esta temática, Marcus Vinícius Fonseca, um dos pioneiros nesses estudos, tem uma obra fundamental, o seu livro A educação dos negros: uma nova face do processo de abolição da escravidão no Brasil. Nesse trabalho, o autor parte das discussões entre os políticos sobre a Lei do ventre livre, 1871, para analisar os debates sobre o fim da escravidão sistêmica no Brasil, os quais estavam interligados com as medidas que o mesmo governo buscava implantar na educação. Em sua tese de doutorado

\footnotetext{
${ }^{9}$ PAIVA, Vanilda Pereira. Educação Popular e Educação de Adultos. $5^{\text {a }}$ edição. São Paulo: Edições Loyola - Ibrades, 1987.

${ }^{10}$ SILVA, José Carlos de Araújo. O Recôncavo baiano e suas escolas de primeiras letras. (1827-1852): Um estudo do cotidiano escolar. Dissertação de mestrado pelo Programa de Pós-Graduação em Educação da Faculdade de Educação da Universidade Federal da Bahia, Salvador, 1999, p36.
} 
discute a presença de crianças negras nas escolas mineiras no século XIX, e junto com Surya de Barros, organiza um livro que já é uma referência importante para a História da educação da população negra: A história da educação da população negra no Brasil. ${ }^{11}$

Diante dessas noções acerca da educação no século XIX, nesse mesmo contexto, a criação das escolas noturnas começou a ser incentivada pelos presidentes provinciais e outras autoridades políticas e educacionais. Os estudos sobre essas escolas, dentre outros, servem de base para compreender como se organizou a educação em fins do Império brasileiro, assim como para entender o processo de alfabetização de trabalhadores jovens e adultos, muitos deles libertos, negros nascidos livres e até mesmo escravizados, a maioria dos casos voltados para homens, mas encontramos sinalizações de mulheres também conectadas a essa escolarização.

Uma das primeiras informações sobre escolas noturnas para mulheres na província da Bahia foi através de um documento elaborado pelo inspetor de educação, Cynildo Pessoa de Barros, enviado à presidência provincial, em 1872, um ano após a "Lei do Ventre Livre". Entre várias medidas apontadas para a educação na Bahia, neste relatório constava uma proposição de criação de escolas noturnas para mulheres para que aprendessem a ler, escrever, fazer cálculos e se tornassem boas mães prendadas nos serviços do lar, basicamente. ${ }^{12}$ Barros só não especificou se era para libertas ou livres. Como na Constituição vigente, a de 1824, só permitia que cidadãos se matriculassem em escolas públicas, pessoas escravizadas eram consideradas indivíduos e não cidadãos, pode-se concluir que a condição de escravizada não estava na proposta do inspetor, caso sua ideia fosse restrita às escolas públicas.

Ele afirmou que "como mãe, a mulher [era] um quadro vivo, se bem preparado, para a educação da prole”. Verifica-se uma visão das aulas noturnas para mulheres que não eram voltadas para o mercado de trabalho, como eram para os homens, mas para desempenhar o papel de mãe. A ideia de escola noturna para mulheres é de grande valia, independente da finalidade proposta por Barros. Tratava-se de um país com mais de $80 \%$ de analfabetos, a oportunidade de alfabetização era algo relevante. ${ }^{13}$ Afinal, poderia ser

\footnotetext{
11 FONSECA, Marcus Vinicius. A educação dos negros: uma nova face do processo de abolição da escravidão no Brasil. Bragança Paulista: Editora da Universidade São Francisco, 2002 e FONSECA, Marcus Vinicius; BARROS, Surya Aarovich Pombo de. (Org.). A História da Educação dos Negros no Brasil. Niteroi/RJ: EdUFF, 2016.

${ }^{12}$ Arquivo Público do Estado da Bahia, relatório do Inspetor Geral dos estudos Cynildo Sely Pessoa de Barros ao diretor da Instrução Pública (26 jan. 1872). Sessão Colonial e Provincial: Documento s/n. Maço 6545 .

13 Censo de 1872. IMPÉRIO DO BRAZIL. Recenseamento do Brazil em 1872. Disponível em: https://biblioteca.ibge.gov.br/Acessado em 31de maio 2019.
} 
um passo para possibilitar também qualificação, se disponibilizassem a elas também alguma formação profissional para terem retorno financeiro, pois em tempos em que a mulher não ocupava cargos no mercado de trabalho de forma considerável, ter esses conhecimentos seria um diferencial no sentido da emancipação pessoal e profissional. ${ }^{14}$

Apesar da defesa de Barros, nenhuma escola noturna para mulher parece ter sido criada naquele ano por incentivo de seu relatório. Ele até indicou a remoção da professora da freguesia de Paripe - na cidade de Salvador - a qual não indicou o nome, para lecionar em escola noturna para mulheres, pois a professora era "uma mestre hábil, casada, de reconhecida moralidade, que estava desaproveitada com dispêndio público, e na sua aula diurna só havia 12 alunas frequentando". ${ }^{15}$ A recomendação do inspetor parece não ter sido relevante para diretoria da Instrução Pública ou não houve mais consideráveis discussões sobre uma possível escola para mulheres funcionando à noite naqueles primeiros anos da década de 1870.

Enfim, essa proposição do inspetor Barros não foi colocada em prática, escolas para esse público não foram criadas de maneira considerável, algumas são encontradas em documentação de maneira pontual e muito mais como tentativa de abertura, através de pedidos de professores e professoras, do que de fato constam como escolas com vários anos de duração. Entretanto, é relevante considerar tais tentativas e as que evidenciam mobilizações para que mulheres que trabalhavam durante o dia ou que queriam aprender uma profissão, estudassem, fossem à escola para saírem da condição de analfabetismo e/ou de subalternidades conferidas por não saberem ler e escrever plenamente, principalmente, mulheres ligadas de alguma forma à condição de cativeiro. ${ }^{16}$

\section{Outras tentativas de Escolas Noturnas para Mulheres}

Em outubro de 1882, o professor Pedro Luis de Jesus solicitou a criação de uma escola noturna para mulheres à direção da Instrução Pública da Bahia. O diretor Romualdo Maria Barroso de Seixas respondeu ao pedido informando que já havia outros

\footnotetext{
${ }^{14}$ Sara Dick analisa a escolarização para mulheres no final do século XIX, principalmente para o nível secundário, muito influenciado pelo Cônego Dom Romualdo Maria de Seixas Barroso. DICK, Sara Martha. As políticas públicas para o ensino secundário na Bahia: o liceu provincial. 1860-1890. Tese de doutorado pelo Programa de Pós-Graduação da Faculdade de Educação da Bahia - Universidade Federal de Bahia. Salvador, 2001.

${ }^{15}$ Arquivo Público do Estado da Bahia, relatório do Inspetor Geral dos estudos Cynildo Sely Pessoa de Barros ao Diretor da Instrução Pública (26 jan. 1872). Sessão Colonial e Provincial: Documento s/n, Maço 6545.

${ }^{16}$ SILVA, José Carlos de Araújo. O Recôncavo baiano e suas escolas de primeiras letras. (1827-1852): Um estudo do cotidiano escolar.
} 
do mesmo tipo. Tal solicitação recebeu o aval da presidência da província, pois esses ofícios eram enviados à direção da Instrução Pública, a qual encaminhava pré-aprovado para o parecer final dado pelo presidente provincial. Pedidos como esses, de acordo com a maioria da documentação pesquisada, eram aceitos, o que poderia atrapalhar a continuidade das escolas era a baixa frequência das pessoas matriculadas ou a falta de móveis, iluminação ou pagamento aos professores. ${ }^{17}$ Porém, sobre esse caso, não foram encontradas mais informações sobre a abertura e continuidade da escola além das informações abaixo:

Pelo seu ofício de 9 do corrente, fico inteirado da intenção que tem Vossa Senhoria, auxiliado por algumas pessoas de boa vontade, em fundar um curso noturno de letras e ciências para o sexo feminino; solicitando ao mesmo tempo que as aulas do dito curso funcionem no edifício ao largo da Piedade, destinado ao Externato Normal de Homens. De acordo com o seu dito ofício, nesta data me dirijo a comissão encarregada da aquisição de prédios escolares para mandar colocar alguns bicos de gás na entrada e nas salas do mesmo edifício, a fim de funcionar as aulas do referido curso. ${ }^{18}$

Algumas aulas para esse público foram solicitadas e concedidas para funcionar num prédio que durante o dia funcionava o externato normal para homens (curso preparatório para o magistério), conforme a declaração do diretor Seixas. Ione Celeste de Sousa aponta outro caso sobre curso noturno para mulheres no ano seguinte à solicitação do professor Pedro Luis de Jesus, por iniciativa da professora Leopoldina Collet, professora de língua pátria no Internato Normal de Senhoras. A professora também pediu permissão ao diretor Romualdo Seixas para que as aulas fossem ministradas na sala anexa ao internato normal (curso em internato preparatório para o magistério), ele concedeu. ${ }^{19}$

No jornal Gazeta da Bahia, em 1882, houve a notícia de que a professora Adélia Franklin da Conceição Lessa abriu uma escola noturna para homens e mulheres na Cruz do Cosme, freguesia de Santo Antônio Além do Carmo, na cidade de Salvador. No jornal estava o seguinte anúncio: “as pessoas que quisessem frequentar as aulas deveriam ser vacinadas. A aula é de sete às nove horas”. ${ }^{20} \mathrm{O}$ critério de vacinação mostra mais um

\footnotetext{
${ }^{17}$ SANTOS, Jucimar Cerqueira dos. Escolas noturnas para trabalhadores na Bahia (1870-1889).

${ }^{18}$ Arquivo Público do Estado da Bahia, ofício de pedido de abertura de escola noturna feminina do professor Pedro Luís de Jesus ao Diretor da Instrução Pública, Romualdo Maria Barroso de Seixas (19 out. 1882). Seção Colonial e Provincial: Documento 1804. Maço 6045. Arquivo Público do Estado da Bahia. Salvador. 19 SOUSA, Ione Celeste Jesus de. Escolas ao Povo: experiências de escolarização de pobres na Bahia 1870 a 1890. Tese de doutorado pelo Programa de Estudos Pós Graduados em História / Pontifícia Universidade Católica de São Paulo: São Paulo, 2006, p. 202.

${ }^{20}$ Hemeroteca digital da Biblioteca Nacional. GAZETA da Bahia. Salvador, 10 mai. 1882. Disponível em: http://memoria.bn.br/DocReader/docreader.aspx?bib=213454\&pesqAcessado em: 11mai. 2017.
} 
elemento de que essa escolarização ia se ajustando à época, tanto à higienização quanto ao sanitarismo, que estavam entre as medidas de mudanças do final do século XIX, mais fortemente após a chegada da República junto às ideias racialistas e de modernização. Outro aspecto que se destaca nesse anúncio é que parecia uma turma mista para homens e mulheres, algo que foi tornando-se mais recorrente no final desse século. ${ }^{21}$ Treze dias depois desse anúncio, a professora requereu ao diretor da Instrução Pública mobílias velhas que ficavam no corredor da repartição das obras públicas para serem usadas em sua escola noturna. Ela recebeu a resposta de que "nada constava na repartição a respeito das mobílias velhas". Esta resposta pode ter sido mais uma forma de considerarem menos relevante as escolas noturnas para aquele público ou não havia mesmo tais mobílias. Mas, se tratando da forma como a educação escolar para mulheres se dava nesse período, como aponta Ana Maria Colling e Elisabeth Juliska Rago, ao discutirem inserção das mulheres no mundo das letras no século XIX, e sendo, possivelmente as candidatas às aulas mulheres que trabalhavam durante o dia, fato que era o mais recorrente entre as mulheres mais pobres e negras daquela sociedades, era mais possível mesmo que a "ausência" das mobílias fosse uma resposta reveladora do pouco caso e/ou dos preconceitos em relação a tal público, mesmo após ter sido permitido o funcionamento das aulas pelo órgão máximo da educação na província. ${ }^{22}$

Em 1888, Hermelinda Valeriano dos Santos solicitou à direção da Instrução Pública a abertura de uma escola noturna para ingênuas e libertas. No dia 8 de junho de 1888, o presidente da província, Manoel Machado Portela, deu o aval para o funcionamento dessa escola e considerou tal iniciativa louvável, "um ato patriótico e humanitário", ${ }^{23}$ No mesmo ano, a professora Maria Olympia de Oliveira teve a concessão para abertura de escola noturna para ingênuas e libertas na povoação do Sacco, região norte da Bahia. ${ }^{24}$ Já após a lei de 1888 e da proclamação da República, houve em manchete do Jornal de notícias que a professora Porphyria Thereza Alves de Oliveira

\footnotetext{
${ }^{21}$ CHALHOUB, Sidney. Cidade febril - Cortiços e epidemias na Corte Imperial. São Paulo, Companhia das Letras, 1996.

${ }^{22}$ Arquivo Público do Estado da Bahia, ofício de solicitação de móveis velhos na da repartição das obras públicas, da professora Adélia Franklin da Conceição Lessa ao diretor da Instrução Pública, Romualdo Maria Barroso de Seixas (22 mai. 1882). Seção Colonial e Provincial: Documento 339. Maço 3350. Arquivo Público do Estado da Bahia. Salvador.

${ }^{23}$ Arquivo Público do Estado da Bahia Ofício de permissão para abertura de escola noturna na rua do Passo da professora Hermelinda Valeriano dos Santos ao presidente da província Manoel Machado Portela (08 jun.1888). Seção Colonial e Provincial: Documento 799. Maço 6580.

${ }^{24}$ Arquivo Público do Estado da Bahia. OFÍCIO de permissão de abertura de escola noturna na povoação do Sacco, ao presidente da província Manoel Machado Portela (14 jun.1888). Documento 817. Maço 6580.
} 
abriu matrícula para uma sessão noturna de aulas também para ingênuas e libertas, em 1898, no colégio Nossa Senhora dos Anjos na ladeira da fonte das pedras, em Salvador. ${ }^{25}$

Essas três últimas iniciativas podem significar um aumento de escolarização para mulheres negras, ainda que não tenha sido em grande quantidade, pois nas últimas décadas do século XIX não eram comuns os pedidos de abertura de escolas noturnas feitos por professoras, muito menos para alunas ingênuas e libertas. Se foram raros os casos de pedido de escola noturna para mulheres, a condição de serem voltadas para ingênuas e libertas se apresenta como algo ainda mais inédito para entender uma sociedade em que a escolarização para mulher, em muitos casos, era voltada para aprender a ser mãe, como cuidar de um lar e aprender os ensinamentos cristãos, como aponta Ian Cavalcante ao pesquisar sobre a escolarização primária de crianças em Salvador no pós-abolição. ${ }^{26}$ Fabiano Silva aponta que, em relação às meninas das "camadas populares", a aprendizagem das letras, ser empregadas domésticas, assim como fazer costura e artesanato poderiam ser fatores que motivavam as famílias a matricularem suas filhas nas escolas, talvez na esperança de ofertar maiores oportunidades no futuro como um casamento ou uma melhor chance de conseguir um trabalho numa fábrica ou no ramo doméstico no período do pós-abolição. ${ }^{27}$ São perspectivas diferentes, mas que evidenciam mais possibilidades de autonomia para essas mulheres que, se não estiveram nas lutas abolicionistas, foram contempladas por tais mobilizações que ainda significavam lutas por mais liberdades, sobrevivência e conquistas de direitos.

É relevante mencionar e refletir acerca do fato de não existirem tantas oportunidades de educação escolar para mulheres, negras ou não negras, e que isso não significa que não houve iniciativas particulares e por parte de mulheres que queriam estudar. Importante destacar também que na abertura de escolas noturnas declaradamente para ingênuas e libertas estava se pensando em escolarização de mulheres negras trabalhadoras diurnas após a lei de abolição da escravidão, muito além da que fez inspetor Barros em 1872, quando propôs a criação de escolas noturnas ao governo, sem especificar que mulheres daquela sociedade seriam contempladas . Fato que aponta para um "olhar"

\footnotetext{
${ }^{25}$ Biblioteca pública do estado da Bahia. Jornal de notícias, 1898, p1.

${ }^{26}$ CAVALCANTE. Ian Andrade. "Pela Instrucção dos filhos do povo”: Escolarização e cultura escolar na Salvador do pós-abolição, 1888-1906. Dissertação de Mestrado pelo Programa de Pós graduação em Educação da Universidade Federal Fluminense, 2015.

${ }^{27}$ SILVA, Fabiano Moreira da. Professorado municipal de Salvador: queixas, crises e greves (1912-1918). Dissertação de mestrado em História Social pelo Programa de Pós-Graduação da Universidade Federal da Bahia, 2017.
} 
mais detido sobre o destino profissional de mulheres com as condições sociais de ingênuas e libertas, fosse para manter uma espécie de controle e direcionamento para o mercado de trabalho livre na condição de criadas, operárias e, infelizmente, até para mantê-las em condições análogas à escravidão em tempos que havia a perspectiva de industrialização com trabalho livre e assalariado no Brasil. Nesses casos, dependia muito de quem partia a iniciativa de criar essas escolas e como essas alunas seguiriam nas aulas, caso se matriculassem e continuassem frequentando. Em contraponto a isso, essas mulheres poderiam também aproveitar tais oportunidades de escolarização para alcançar o nível secundário ou o superior, trabalharem de maneira descolada de atividades que eram típicas do tempo da escravidão sistêmica, enfim, trabalhar no que tivessem interesse, serem sobre si. ${ }^{28}$ Fica posto que mesmo de maneira embrionária, mulheres, e alguns homens, voltaram atenção para a alfabetização de mulheres, algumas delas negras e que vivenciaram condições de cativeiro, que com determinado tempo depois ou para as gerações seguintes poderiam alcançar outros níveis escolares com profissões de status secular, como nas áreas de direito e medicina.

A questão de escolas noturnas para mulheres das camadas populares na Bahia no século XIX dialoga com a discussão sobre a ausência de mulheres nas escolas desse período. Eliane Peres, ao abordar a escola noturna na Biblioteca pelotense, identifica a ausência de mulheres nessa escola e afirma que essa é uma das questões principais de sua análise e, portanto, a presença exclusivamente masculina naquele espaço. Para Peres, o mais comum nas escolas que tinham mulheres era o ensino também ser voltado para conselhos, recomendações, ditos, provérbios e poesias sobre a condição feminina. Propuseram-se a "ensinar" como as mulheres deveriam ser ou como deveriam agir diante do seu papel de mães e esposas, tal qual consta no relatório do inspetor da Instrução Pública Bahia, em 1872. ${ }^{29}$ Isto indica, de alguma forma, como esta prática era comum em diversos e distantes lugares do país. A autora ainda aponta que a escola noturna da biblioteca pelotense era para homens brasileiros e estrangeiros, de 9 a 48 anos, entre os anos de 1875 e 1915 com aulas também de História e Geografia, além de inglês e francês. ${ }^{30}$ Outro ponto importante a se refletir é que a autora, mesmo problematizando a

\footnotetext{
${ }^{28}$ Hemeroteca digital da Biblioteca Nacional. Jornal de notícias, Bahia, 26 de janeiro de 1898. Disponível: http://memoria.bn.br/DocReader/DocReader.aspx?bib=222216. Acessado em 31 de outubro, 2019.

29 PERES, Eliane. Templo de Luz: Os Cursos noturnos masculinos de Instrução primária da Biblioteca Pública Pelotense 1875 - 1915. Pelotas, RS: Seiva publicações, 2001, p. 48.

${ }^{30}$ PERES, Eliane. Templo de Luz: Os Cursos noturnos masculinos de Instrução primária da Biblioteca Pública Pelotense 1875 - 1915.
} 
ausência de mulheres nessa escola, não discute que mulher seria essa para tal escola noturna, se livre, liberta ou ingênua, apresentando uma visão geral dessa ausência, o que evidencia uma lacuna na análise para compreender as mulheres negras como integrantes de um dos maiores contingentes de trabalhadoras do Brasil, mesmo que nessa região existissem quantidade considerável de trabalhadoras brancas, muitas delas, vindas da emigração europeia, que não tiveram um passado de escravidão e que não eram filhas de pai e/ou mãe escravizados.

No Ceará a situação não diferia muito. Destacou-se o Colégio Imaculada Conceição por manter, no mesmo prédio onde funcionava o ensino particular, um curso dominical voltado para moças. Em 1889, um ano seguinte à lei de abolição da escravidão, foi registrada a frequência de 190 alunas que, aos domingos, aprendiam a ler, escrever e contar. Esse atendimento tão expressivo foi mantido nos anos seguintes, quando se registrou uma frequência superior a duzentas moças pobres. Em maio do mesmo ano, foram iniciadas as aulas noturnas para o sexo feminino, na Escola Elisa Schi, situada em endereço diferente, à rua Dr. Pedro Borges, com matrícula de 68 alunas, tinha à frente as professoras Porfiria Lopes Barroso e Cecília Ferreira de Melo. ${ }^{31}$

Casos como os da Bahia, Pelotas e do Ceará evidenciam os direcionamentos dados à escolarização de mulheres na época e as dificuldades de conferir essas oportunidades tais quais eram para homens, com muito mais dificuldades quando se tratavam de mulheres libertas e escravizadas, em uma sociedade em que saber ler, escrever, contar e ter outros conhecimentos escolares era motivo de distinção social e a chance de elevação de condições econômicas.

Após abordarmos alguns aspectos do ensino primário para mulheres no final do século XIX, buscaremos discutir a inserção das mulheres no curso superior no Brasil a partir da singular trajetória da primeira médica negra da Faculdade de Medicina da Bahia: Maria Odília Teixeira. Usaremos sua formação na Faculdade de Medicina da Bahia (FAMEB) para entender a instituição e os debates raciais que esta produzia, bem como as produções acadêmicas do período. Evidenciamos a sua presença, sendo uma mulher de cor na instituição, e o que isso representava dentro e fora dos muros da FAMEB. Ao final, abordamos as teses doutorais que discutiam o mesmo assunto que a médica se

\footnotetext{
${ }^{31}$ DAMASCENO, Ana Daniella. Escolas Noturnas no Ceará: Ações de combate ao analfabetismo adulto na Primeira República. Dissertação de mestrado pelo Programa de Pós-graduação do Centro de Educação - Universidade Estadual do Ceará. Fortaleza, 2010, p. 81.
} 
propôs a debater, e que nunca havia sido levantado por nenhuma pioneira: a cirrose alcoólica.

\section{Uma trajetória: Maria Odília Teixeira}

No mesmo período em que homens e mulheres, da população pobre, de cor, livres ou libertos, lutavam para serem inseridos em espaços escolares que lhes forneceriam a educação primária, o debate acerca da entrada das mulheres no ensino superior no Brasil se acalorou. Tornou-se cada vez mais perceptível a participação feminina, em sua maioria advinda da elite, em espaços de intelectualidade, sobretudo nos que envolviam as letras. Essas mulheres recorriam a estratégias, por vezes individuais, para transpor e alargar a possibilidade de estudar no ensino superior. No campo específico da medicina, encontramos as primeiras que conseguiram alcançar a formação ainda fora do país. A pioneira no ensino superior foi Maria Augusta Generoso Estrela, que só pôde alcançar seu intento por reunir condições específicas, segundo Colling:

Em 1875, uma jovem de 14 anos, Maria Augusta Generosa Estrela deixou o Rio de Janeiro para estudar Medicina nos Estados Unidos. Resolveu fazer o curso após ter lido um artigo em o Novo Mundo, jornal brasileiro publicado em Nova Iorque, sobre uma mulher americana que tinha obtido um diploma de médica. Além do pai e amigos, o próprio Imperador concedeu-lhe assistência financeira, concedendo-lhe uma bolsa de 100000 réis até sua formatura. Maria Augusta era uma exceção. ${ }^{32}$

Só fora do país e com o apoio do Imperador foi possível que Maria Augusta se formasse em medicina, em 1881. O patrocínio para que estudantes fossem ao exterior era uma prática frequente feita pelo Imperador. Não há um levantamento quantitativo de todas as bolsas e/ou auxílios concedidos por D. Pedro II, mas é notório que os estudantes homens foram maioria entre os beneficiados:

D. Pedro II patrocinava, particularmente, projetos de pesquisa de documentos relevantes à história do Brasil, no país e no estrangeiro. Ajudou, de várias formas, o trabalho de vários cientistas como Martius, Lund, Agassiz, Derby, Glaziou, Seybold e outros. Financiou ainda vários profissionais como agrônomos, arquitetos, professores, engenheiros, farmacêuticos, médicos, pintores etc. Um exemplo famoso é o de Guilherme Schuch, futuro Barão de Capanema. ${ }^{33}$

32 COLLING, Ana Maria. As primeiras médicas brasileiras - Mulheres à frente de seu tempo. FRONTEIRAS: Revista de História, v. 13, n. 24, p. 169-183.

33 TRINDADE, Diamantino Fernandes; TRINDADE, Laís dos Santos Pinto. Os Pioneiros da Ciência Brasileira: Bartholomeu de Gusmão, José Bonifácio, Landell de Moura e D. Pedro II. Revista Sinergia, 2003, v. 4, p. 163-169. 
Muitas pioneiras da medicina buscaram incutir em seus pais a vontade que possuíam de cursar o ensino superior para que assim fosse possível que se tornassem médicas. O advogado e jornalista pernambucano, Clodoaldo Alves de Oliveira, pai de Josefa Águeda Felisbella Mercedes de Oliveira, entrou com uma petição no ano de 1878 para que sua filha pudesse estudar medicina fora do país. Talvez motivada pelo exemplo de Maria Augusta Generoso Estrela, Felisbella reverteu o jogo para seu lado utilizando argumentos jurídicos e mobilizando um agente masculino como facilitador para superação de sua condição limitada pelo próprio patriarcado. Infelizmente a sua petição defendida por Tobias Barreto foi negada, ainda assim ela conseguiu viajar para estudar no New York Medical College for Women. Em Nova Iorque, conheceu Maria Estrela e juntas escreveram um jornal que:

\begin{abstract}
Adotando as mesmas convicções feministas, que enfatizavam a necessidade da educação superior para as mulheres, publicaram em 1881, o jornal literário $A$ Mulher, em Nova York e distribuído nas principais capitais brasileiras. $A$ Mulher fora "projetado para convencer as mulheres brasileiras de suas aptidões latentes, e para mostrar que 'tanto a mulher como o homem se podem dedicar ao estudo das ciências"", 34
\end{abstract}

Em 1879, após longos debates sobre a entrada das mulheres no ensino superior, foi aprovada a Reforma Leôncio de Carvalho. Dentre outras coisas, esta reforma no ensino possuía o "Artigo 24 do Decreto do Império n 7.247 de 19 de abril de 1879, que concedia às mulheres o direito de inscrição nos cursos de Medicina de Salvador (Bahia) e do Rio de Janeiro" "35; o que tornou realidade um anseio antigo de muitas mulheres. Essa reforma foi a concretização de uma longa discussão em que a educação feminina era tema central, e em que diversas vertentes de pensamento apresentaram e debateram seus argumentos, para as mulheres significou uma grande batalha vencida. Com essa conquista ao direito da educação superior, as que conseguiam acessá-lo, tiveram muitos desafios para desenvolver seus estudos.

O entrave poderia começar com a desconfiança que a sociedade tinha em ter as mulheres da elite, em sua grande maioria brancas ou lidas como tal, transitando nas ruas e ocupando os bancos escolares junto aos homens. Além desse obstáculo que se referia ao gênero, havia as dificuldades compartilhadas com todos os estudantes de medicina, pois era necessária uma preparação prévia para desenvolver o curso, sendo exigido o

\footnotetext{
${ }^{34}$ RAGO, Elisabeth Juliska. A ruptura do mundo masculino da medicina: médicas brasileiras no século XIX. Cadernos, 2000. n. 15, p. 215.

${ }^{35}$ MEIRELLES, Nevolanda Sampaio et al. Teses doutorais de titulados pela Faculdade de Medicina da Bahia, de 1840 a 1928. Gazeta Médica da Bahia, 2008, v. 74, n. 1, p 11.
} 
domínio de línguas como o latim e o grego. As despesas provenientes das matrículas e do material para o curso, quando somadas, alcançavam um valor que só poderia ser atingido por estudantes provenientes de famílias ricas ou que contassem com patrocínio em seus estudos.

Muitas pioneiras tiveram que buscar estratégias mais elaboradas para atingir a faculdade de Medicina, iniciando estudos mais avançados no curso de Letras e Ciências, que lhe conferiram uma profissão garantida e certa "respeitabilidade". Encontramos essa noção moral atrelada a lecionar, no já mencionado pedido de transferência de uma professora, feito pelo Inspetor Barros em 1872, em que o mesmo recorre aos adjetivos: "um mestre hábil, casada, de reconhecida moralidade...". Como destaca Mott, "a atividade de professora era uma das poucas profissões consideradas respeitável para mulheres"36. Em outra instância, encontramos pioneiras que usaram o ofício de educar para financiar os seus estudos em outras áreas do conhecimento, ou como o único meio de adentrar ao "mundo das letras", seja por aceitação da família ou por limitações financeiras.

A jovem Maria Odília Teixeira, nos últimos momentos do século XIX, foi a Salvador buscando a preparação que deveria ter, caso decidisse prosseguir em seus estudos. Em seu horizonte havia algumas possibilidades: o curso de medicina ou tornarse professora. A moça vinha de uma tradicional família de Cachoeira- São Félix que trazia como principal legado a medicina, sendo seu tio-avô, seu pai, além de seu irmão Joaquim Teixeira, que à época já cursava medicina, suas referências no “dever de medicar". Em sua bagagem, além dos livros e roupas, carregou consigo o nome de seu pai e a cor de sua mãe, já que Odília era filha de um casal interracial. Essa longínqua união entre seus pais, José Pereira Teixeira e Josephina Luiza Palma, ele médico formado pela FAMEB e clínico conhecido e respeitado em todo o Recôncavo, ela uma mulher de cor, neta de uma escrava alforriada e que infelizmente pouco sabemos, gerou uma prole de 5 filhos, dentre eles Maria Odília.

Como, segundo afirma José Léo ${ }^{37}$, filho de Maria Odília, o pai dela não possuía o dinheiro necessário para mantê-la estudando, o seu patrocinador foi seu irmão mais velho, Tertuliano Teixeira, que, desenvolvendo a profissão de rábula, tornou-se "o rico

\footnotetext{
${ }^{36}$ RAGO, Elisabeth Juliska. A ruptura do mundo masculino da medicina: médicas brasileiras no século XIX. Cadernos Pagu, 2000, n. 15, p. 205.

${ }^{37}$ LAVIGNE.J. L. José Léo Lavigne: depoimento [maio 2015]. Caldas do Jorro, Bahia, 2015. Áudio mp3 (51:07). Entrevista concedida.
} 
da família". Com sua matrícula ${ }^{38}$ no bacharelado de Letras e Ciências do segundo ano datando de 1899, Odília teria começado seus estudos no ano de 1898. Segundo Lima, “o aluno que completasse sete anos de Ginásio recebia o grau de Bacharel em Letras e Ciências, adquirindo, assim, direito à matrícula nas escolas de nível superior e preferência nas nomeações para o magistério nos estabelecimentos de instrução secundária". 39

As disciplinas aprendidas nos sete anos de ensino versavam sobre as mais variadas ciências e línguas, como grego, francês, latim, história natural e geometria. É notório que a gama de disciplinas ministradas era o tipo de preparação destinada à elite baiana, em sua maioria masculina, pois ao sair do Ginásio da Bahia esses estudantes estavam a um passo de ocupar os bancos escolares do ensino superior.

Diferente de muitas moças do Recôncavo, das classes mais abastadas, que iam a Salvador "apenas por ocasião de moléstias ou para cumprir promessa de uma romaria ao Senhor do Bomfim" ${ }^{40}$, com a idade entre 15 e 16 anos, ${ }^{41}$ Odília buscou na capital uma instrução superior à que muitas mulheres do interior, mesmo as de posses, poderiam alcançar. Para muitas moças em idade similar à de Odília, a ida a Salvador representava "civilizar-se, tirar a "casca de tabaroas", ${ }^{42}$ o que não significava acessar escolas de ensino formal da capital e sim o ensino limitado às prendas domésticas e ao mundo considerado feminino. Em 1910, um ano após ter se formado em medicina, Odília pode ter lido no jornal cachoeirano A Ordem, o seguinte artigo: "O que devemos ensinar para nossas filhas", onde um autor desconhecido elencou o que deveria ser ensinado às moças de Cachoeira e São Félix. O autor do artigo destacou o que achava importante nesse ensino: "Dá-lhe uma instrução elementar. Ensine-as a preparar alimentos substanciosos, a lavar, a engomar, remendar meias e fazer sua própria roupa". ${ }^{43}$

Caso algum leitor resolvesse aceitar esse conselho sobre a instrução feminina, poderia matricular sua filha de imediato no curso ofertado pelo "Asylo filhos de Anna",

\footnotetext{
${ }^{38}$ Arquivo Histórico do Colégio Central da Bahia. 1A - Série referente à Matrículas de alunos (as). Livro n. 17. Matrícula em 08 de fevereiro de 1899. Matrícula 42.

${ }^{39}$ LIMA, Déborah Kelman. O Banquete Espiritual da Instrução: o Ginásio da Bahia, Salvador: 18951942. Dissertação de Mestrado pelo Programa de Pós-Graduação em História Social, Universidade Federal da Bahia, 2003, p 24.

${ }^{40}$ REIS, Adriana Dantas. Cora: lições de comportamento feminino na Bahia do século XIX. Universidade Federal da Bahia, Centro de Estudos Baianos, 2000, pg. 65.

${ }^{41}$ Arquivo Histórico do Colégio Central da Bahia. 1A - Série referente à Matrículas de alunos (as). Livro n. 17. Matrícula em 08 de fevereiro de 1899. Matrícula 42

${ }^{42}$ REIS, Adriana Dantas. Cora: lições de comportamento feminino na Bahia do século XIX, pg. 65.

${ }^{43}$ Biblioteca Pública do Estado da Bahia. O QUE devemos ensinar para nossas filhas. A Ordem, Cachoeira, 6 de agosto de 1910, p. 1.
} 
que oferecia um "curso de primeiras letras, francês e prendas para meninas". ${ }^{44} \mathrm{O}$ posicionamento tomado neste artigo nos leva a constatar que apesar de já ter duas décadas que as mulheres acessaram o ensino superior, não havia consenso sobre a educação feminina; e que os argumentos utilizados para inviabilizar esse acesso ainda poderiam se fazer presentes em vários cenários. Esse argumento ganhou mais força ao constatarmos que ainda na educação primária, muitas freguesias da capital baiana, a esta altura, ainda não contavam com uma oferta de ensino para a maior parte da população, sobretudo pobre e de cor, mesmo com a especificidade da modalidade noturna, ficando notório que a tensão e a disputa pelos espaços dos saberes continuavam nas diversas instâncias.

Numa das instituições de ensino mais prestigiada de Salvador, o Ginásio da Bahia, a jovem Odília decerto se destacou, pois foi a única mulher entre os formados no começo de 1904. Neste mesmo ano, dos 119 alunos matriculados constam apenas 7 moças. Entre seus colegas de turma, Eduardo José de Oliveira e Galdino Pereira de Castro se distinguiram por terem seguido o mesmo caminho que Maria Odília, tornando-se bacharéis em medicina, o primeiro inclusive sendo da mesma turma que ela na FAMEB ${ }^{45}$. Além do gênero de Odília, a sua cor foi outro marcador importante no período em que estudou no Ginásio da Bahia. A pesquisa ${ }^{46}$ de Lima remonta quantitativamente a participação de alunas negras na instituição, e ainda que não tenha alcançado a presença de Odília, e de outras mulheres negras para o período anterior ao contabilizado, seus dados fornecem base para vislumbrar a excepcionalidade de sua presença levando em consideração dois marcadores centrais de sua trajetória: gênero e cor. As informações sobre a presença dos homens e mulheres negras em uma instituição de ensino, como o Ginásio da Bahia, atestam que após a primeira década do 13 de maio a população negra não fazia parte dos projetos republicanos.

\footnotetext{
${ }^{44}$ Biblioteca Pública do Estado da Bahia A Ordem, Cachoeira, 15 de janeiro de 1910, p. 3.

${ }^{45}$ OLIVEIRA, Eduardo José de. Da responsabilidade Médica. FAMEB: 102-O. Lista de Teses. Gazeta Médica. pg. 73. 2004.

${ }^{46}$ Em seu estudo sobre o Ginásio da Bahia, Lima chega à conclusão de que "Cruzando-se os indicadores, cor e gênero, para os períodos 1936-1937 e 1940-1942, observa-se que era bastante limitado o acesso de mulheres negras ao Ginásio". Ainda que o discurso mantido pela maioria de seus entrevistados aponte para "[...] uma convivência democrática, onde não havia discriminação" [39], os dados sugerem a pouquíssima participação de mulheres de cor na instituição. Apesar de a análise ser das décadas seguintes à passagem de Odília pela instituição, esses dados apontam a singularidade da sua experiência e dificuldade que ela pode ter passado. A presença de mulheres negras na terceira e quarta década do século XX se fez quase nula, nos anos entre 1936 e 1937, sendo inexistente entre 1940 e 1942 de $0,8 \%$; nos anos em que Odília se matriculou, sequer foi contabilizada. Para os homens negros as possibilidades estavam um pouco mais alargadas, foi registrada a sua presença entre os anos de 1936 e 1937 em 7,3\% e, em entre 1940 e 1942 em $4,3 \%$.
} 
O crucial para que Odília pudesse acessar um espaço de conhecimento privilegiado, como o Ginásio, foi o fato de que se por um lado ela pertencia à classe racial que estava "excluída do processo produtivo" e, por conseguinte, educacional no período republicano, por outro havia a presença e influência de seu pai: um homem branco, médico e de família influente. Decerto que a sua ascendência branca, ressignificada e utilizada em recomendações, influências e prestígio; juntamente com o dinheiro que seu irmão tinha, possibilitaram que ela conseguisse se formar em março de 1904 e adentrar no ensino superior na FAMEB.

A petição feita ao Diretor Alfredo Thomé de Britto, no dia 16 de março de 1904, antes mesmo de ter em mãos o diploma de Bacharela em Ciências e Letras do Ginásio da Bahia, denota certa pressa em ingressar ainda naquele ano no curso de medicina. Se esse era o intento de Odília e, se até mesmo esse plano foi acordado anteriormente com sua família, as fontes não evidenciam. No entanto, os esforços empregados para que ela pudesse ter o melhor estudo fornecido para os "filhos da elite" indicam que este plano poderia estar há muito tempo no horizonte da jovem bacharela. Pode-se conferir a Odília outros fatores que corroboraram em sua escolha e, até mesmo, analisar se de fato houve uma escolha.

Maria Odília decerto estava atenta a esses debates e às possibilidades apresentadas no cenário de negociações que as duas pioneiras apresentaram para ela, e para outras mulheres, que puderam vislumbrar uma fagulha de esperança no sonho de estudar. Além de uma escolha e/ou aptidão prévia, o capital familiar pode ter contribuído de forma decisiva para a sua profissão. Em uma carta escrita por Odília em defesa da memória de seu pai, intitulada "Estabelecendo a verdade", ela relata que, "pois meu pai, ajudado por excelente memória, era um erudito, que sabia dizer com graça, humorismo e vernaculidade horas a fio, sem cansar os ouvintes" ${ }^{\natural 7}$. Se, como Maria Odília afirmou, seu pai fosse um homem erudito, que cultivou até seus últimos dias as letras e a ilustração, não é difícil imaginá-lo como um homem sensível à instrução da filha. Unido a isso poderia haver um desejo do médico de que não só seu filho Joaquim Teixeira, como sua filha, levasse sua profissão à frente tornando-a um legado familiar. Sobre a influência paterna, Silva e Taveira, indicam algumas possibilidades: alguns estudos encontraram uma forte relação entre famílias com estatuto socioeconômico elevado e a orientação para a carreira e/ou opção por carreiras pioneiras por parte das filhas. Outros estudos, na

\footnotetext{
${ }^{47}$ LAVIGNE. Os meus 87 anos outros assuntos. Salvador, Bahia. Editora Mensageiro da Paz. 1971, p.123.
} 
mesma linha, verificaram que as mulheres que têm profissões onde os homens dominam têm maior probabilidade de terem pais que são profissionais nessas áreas. ${ }^{48}$

Em 1904, ano de entrada de Maria Odília na FAMEB, já haviam se doutorado 7 mulheres na instituição, até então nenhuma negra. ${ }^{49}$ Ao passo que a continuidade de seus estudos, no contexto geral, representava o alargamento que as mulheres, sobretudo de elite, começaram a conquistar no último quartel do século XIX, também se constitui no terreno da excepcionalidade. Desde 1898, com a formatura de Laura Amalia de Souza Bahiense, nenhuma mulher havia se matriculado no curso de medicina; Maria Odília inaugurou, assim, a participação feminina no século XX no curso.

Em sua turma, a estudante "dividiu” os bancos escolares com 48 homens, tendo contato com somente 5 mulheres que, muito provavelmente, estavam fazendo o curso de parteiras, instituído em 1832. A condição de gênero atrelada a sua cor, tornava-a um destaque neste ambiente, pois a FAMEB já havia experimentado, desde seus primórdios, em seus quadros a presença masculina de cor. No período em que funcionou a Escola Cirúrgica foram 5; passando a Colégio Médico e Cirúrgico da Bahia, 2; quando tornouse Faculdade de Medicina da Bahia o quadro de alunos de cor chegou a 14; quanto aos professores, foram levantados 8 desde sua fundação até 1888. Como explica Furtado, a classificação racial dos docentes e discentes citados foram feitas "através de autoafirmação, afirmação de biógrafos, historiadores, desenhos, retratos em telas a óleo, fotografias etc." 50

No ínterim de sua formação, entre 1904 e 1909, Maria Odília viveu o apogeu dos estudos ligados aos chamados estudos médicos legais. Ainda que parte de sua ascendência fosse proveniente de seu pai, um homem branco, médico e de boas relações, fatores determinantes para seu ingresso no curso de medicina, a sua cor não estaria invisibilizada, nem despercebida nesse ambiente, pois como apontou Carone, "não é posto nem é dito, mas pressuposto nas representações que exaltam a individualidade a neutralidade racial do branco - a branquitude - reduzindo o negro a uma coletividade racializada pela

\footnotetext{
${ }^{48}$ ASTIN, 1984.e.g., Hoffman, Goldsmith, \& Hofacker, 1992.In: SILVA, Ana Daniela; TAVEIRA, Maria do Céu. Educação e desenvolvimento de carreira das mulheres. Ex aequo, n. 25, p. 165-178, 2012.

${ }^{49}$ Chegamos a essas afirmações a partir de informações retiradas da Memória Histórica da FAMEB. Ver em: FORTUNA, Cristina Maria Mascarenhas. Memórias Históricas da Faculdade de Medicina da Bahia. 1916-1923; 1925-1941. ANEXO 1 e ANEXO 2. Faculdade de Medicina da Bahia. Salvador. Bahia, Brasil. ${ }^{50}$ FORTUNA, Cristina Maria Mascarenhas. Sobre os afrodescendentes, abolicionismo, estudos sobre o negro e a Faculdade de Medicina (F.M.B.). Primaz do Brasil de 1808 a 1888. Faculdade de Medicina da Bahia. Salvador. Bahia, Brasil. p. 52.
} 
intensificação artificial da visibilidade da cor e de outros traços fenotípicos aliados a estereótipos sociais e morais." 51

Não sabemos até que ponto sua presença pode ter influenciado, nem em que dimensão, os estudos ali produzidos. Sobre essa possibilidade, Keller aponta:

\begin{abstract}
Mas se reformulássemos a questão e perguntássemos se sua presença ajudou a restaurar a equidade no domínio simbólico em que o gênero operou por tanto tempo, responderia com um inequívoco sim. Especialmente, diria que a presença corriqueira de mulheres em posições de liderança e autoridade na ciência ajudou a erodir o sentido de rótulos tradicionais de gênero no próprio campo em que trabalhavam, e para todos os que estavam trabalhando nesse campo. $^{52}$
\end{abstract}

Como tema de sua tese doutoral, Maria Odília escolheu tratar do mal causado pelo alcoolismo: a cirrose alcoólica. Sendo a primeira médica graduada em terras baianas no século XX, ela pode ter ousado em sua escolha de tema ao vislumbrar para sua carreira outras possibilidades que não se limitassem à ginecologia ou obstetrícia. Essa possibilidade torna-se mais pautável ao constatarmos que a Reforma de ensino Epitácio Pessoa, de 1 de janeiro 1901, não apontava em nenhum de seus artigos que fossem feitos os sorteios do ponto, com o tema para as teses doutorais que seriam defendidas pelas (os) estudantes de medicina. Sendo assim a vanguarda de Maria Odília é inegável, pois:

\begin{abstract}
Sua tese inaugural foi "Algumas considerações acerca da curabilidade e do tratamento das Cirrhoses Alcoólicas". As outras seis mulheres formadas pela Fameb antes tiveram como tema da tese inaugural ou em tocoginecologia ou em pediatria. Maria Odília amplia a escolha temática ao abordar a questão da cirrose alcoólica. ${ }^{53}$
\end{abstract}

O alcoolismo naquele período já vinha sendo há muito tempo discutido por outros médicos, sendo recorrente a aproximação e/ou o uso das teorias racialistas e higienistas para tratar do tema. A médica optou por não discutir os aspectos sociais da doença, nem atribuiu fatores genéticos e raciais às pessoas que desenvolviam a cirrose alcoólica. Diferente de muitos contemporâneos, Odília não recorreu a nenhum pressuposto de tais teorias. Essa escolha pode significar a sua preferência em manter a

\footnotetext{
${ }^{51}$ CARONE apud VILHENA, J. de. A violência da cor. Sobre racismo, alteridade e intolerância. Revista Psicologia Política, 2006 v. 6, n. 12, p. 391-413.

52 KELLER, Evelyn Fox. Qual foi o impacto do feminismo na ciência. Cadernos Pagu, 2006, v. 27, n. 27, p. 32.

53 JACOBINA, Ronaldo Ribeiro. Memória histórica do centenário da Faculdade de Medicina da Bahia (2008): os professores encantados, a visibilidade dos servidores e o protagonismo dos estudantes da FMB. Salvador: EDUFBA, Faculdade de Medicina, 2013.
} 
discussão científica nos parâmetros delimitados pela proposta do estudo, e/ou até mesmo pode estar atrelada a sua própria condição racial.

Neste ambiente em que algumas pioneiras já tinham travado suas primeiras batalhas e vencido, embora houvesse uma estrutura altamente masculinizada e em que o racismo científico encontrou esteio, foi que Maria Odília desenvolveu seus estudos alcançando o grau em medicina. Certamente sua cor e seu gênero colocaram a estudante no centro das atenções; o artigo feito em sua homenagem na ocasião de sua formatura dá alguns indícios: "É belo vê-la na simplicidade, fidalga de seu traje costumeiro, sobrolhos carregados, sem mostras de rancor, o olhar dizendo tudo o que se acostela no seu mundo psíquico, pesando o passo, num relevo de esperta, fugindo ao bulício que possa fazer a sua passagem." $" 54$

Alguns pontos chamam atenção na descrição apresentada de Odília, como a não demonstração de um rancor e a fuga de um bulício, ou seja, qualquer burburinho ou tumulto por sua presença. Tais quais outras estudantes de medicina anteriores à sua presença, Maria Odília decerto encontrou dificuldades, quiçá hostilidades, dentro da FAMEB. Aqui destaco a vitória dessas pioneiras da medicina, que buscaram estratégias para entrar e permanecer dentro deste espaço; quer seja da presença de um irmão no mesmo curso para acompanhá-las, ou até mesmo adotando uma postura de "simplicidade" $" 55$ para alcançar o seu objetivo maior, que nada tinha de simples, o sonho de ser médica.

Sonho esse alcançado, segundo Silva, "aos quinze dias do mês de dezembro de 1909, vestida em sua beca, braço dado ao seu pai, subiu as escadas do salão nobre da tradicional Faculdade de Medicina da Bahia para receber o grau de doutora, a primeira médica brasileira negra. Dra. Odília venceu o desafio". ${ }^{56}$ Mais uma vez, Odília surgiu de braços dados com o pai - Josephina, a mãe, negra, estava ausente ou foi invisibilizada. Segundo a Memória Histórica de 1909, Maria Odília teria prestado o juramento no dia 13 de dezembro de 1909 na secretária da $\mathrm{FAMEB}^{57}$, não participando assim da colação de grau solene. Outra afirmação feita no artigo de Silva, que infelizmente esta pesquisa não pode alcançar, foi sobre a médica ser a primeira médica negra do Brasil. A manutenção

\footnotetext{
${ }^{54}$ DUTRA in: LAVIGNE, Eusínio. Meus 87 anos e outros assuntos. Salvador. Bahia. 1971, p116.

${ }^{55}$ DUTRA in: LAVIGNE, Eusínio. Meus 87 anos e outros assuntos. Salvador. Bahia. 1971, p116

${ }^{56}$ SILVA. Benedicto Alves de Castro. A cachoeirana Doutora Odília Teixeira Lavigne. Gente e memória. A Tarde. 2011, p6.

${ }^{57}$ Arquivo da Faculdade de Medicina da Bahia, UFBA. CARVALHO. José Eduardo Freire. Memória Histórica da Faculdade de Medicina da Bahia. 1909.
} 
do importante arquivo do alunado de medicina do Rio de Janeiro nos impediu de verificar essa poderosa afirmativa. Contudo, nos juntamos a Benedicto Silva em sua máxima assertiva "Odília venceu o desafio.", pois a médica representava uma conquista feminina importante, ainda que em primeira instância alcançasse as mulheres de elite, em ocupar os bancos escolares do ensino superior no Brasil.

\section{Considerações Finais}

No Brasil, as discussões sobre mulheres estudando em espaços escolares ainda precisam de mais produção bibliográfica e, na mesma medida as condições em que estas atuaram como profissionais. No caso das mulheres negras a necessidade é maior, trata-se de uma maioria e em condições historicamente desvantajosas. Ainda que as trabalhadoras existissem muito antes mesmo da industrialização e do capitalismo, no século XIX, passou-se a discutir a moralidade, as implicações e o controle sobre essas mulheres que transitavam no espaço público participando, sendo e modelando uma parcela importante do mundo do trabalho. Na Bahia, especificamente, essas condições não destoam dos demais lugares do país. As possibilidades de educação escolar em qualquer nível para mulheres não foram diferentes, com ressalva para a feminização do magistério e nos casos do comércio urbano, como o serviço de ganho, até mesmo por se evidenciarem como categorias profissionais de pouco prestígio e reconhecimento financeiro já no final do século XIX. ${ }^{58}$

Existiram oportunidades de escolarização para mulheres negras, sendo muito possível que até mais do que o trazido à baila nesse texto, mas que não conseguimos conhecer ainda por conta da documentação não evidenciar tantos casos oficialmente. Os casos já apresentados são úteis por darem pistas para aventarmos sobre a aprendizagem das primeiras letras em ambiente mais privados, em circunstâncias mais corriqueiras e utilitárias para essas mulheres servirem a senhores, senhoras, patrões e patroas, mas que lhes conferiram a ampliação de horizontes para outras possibilidades de condições de vida para além da que tiveram e que tiveram suas ancestrais.

Os debates acerca da educação escolar para mulheres tinham como maior alvo de preocupação as mulheres de classe alta e brancas. Elas passaram a ter a oportunidade de estudar também nas universidades do Brasil, após a reforma Leôncio de Carvalho, em

\footnotetext{
58 VILLELA, Heloisa de Oliveira S. O mestre-escola e a professora. In: LOPES, Eliane Marta Teixeira; FARIA FILHO, Luciano Mendes; VEIGA, Cynthia Greive (org) 500 anos de educação no Brasil. Belo Horizonte: Autêntica, 2000.
} 
1879. Diferente das mulheres da camada mais pobre da população, que em grande maioria trabalhava, e tinha a rua como espaço corriqueiro em seu dia a dia, as futuras médicas haviam sido criadas na lógica patriarcal que diferenciava e delimitava onde estas poderiam transitar e, sobretudo, com que objetivo esse trânsito deveria ser feito. Desde a implantação do sistema escravista no Brasil, o espaço público permitiu à massa de mulheres negras, escravizadas, livres ou libertas, algumas possibilidades, parte delas, provocadas por essas próprias mulheres.

No início do século XX, no Brasil, as mulheres já experimentavam avanços na luta pelos mesmos direitos civis que os dos homens. A trajetória de mulheres negras na educação escolar, a qual Maria Odília fazia parte, dá mostras que essas conquistas se tornavam cada vez mais pautáveis. O caminho é ainda muito longo, é preciso muito mais igualdade de oportunidade e condições, afinal, as mulheres compõem a maioria da sociedade brasileira, e as negras, a maioria entre as mulheres.

Data de submissão: 01/11/2019

Data de aceite: 04/04/2020 


\section{Referências Bibliográficas}

ALBUQUERQUE, Wlamyra Ribeiro de. O Jogo da dissimulação: abolição e cidadania negra no Brasil. São Paulo: Companhia das Letras, 2009.

ASTIN, 1984.e.g., Hoffman, Goldsmith, \& Hofacker, 1992.In: SILVA, Ana Daniela; TAVEIRA, Maria do Céu. Educação e desenvolvimento de carreira das mulheres. Ex aequo, n. 25, p. 165-178, 2012.

CARNEIRO, Maria Elizabeth Ribeiro. Procura-se "preta, como muito bom leite, prendada e carinhosa": uma cartografia das amas-de-leite na sociedade carioca (18501888). Tese de doutorado defendida no Programa de Pós-Graduação em História da Universidade de Brasília, Brasília, 2006.

CARONE apud VILHENA, J. de. A violência da cor. Sobre racismo, alteridade e intolerância. Revista Psicologia Política, 2006 v. 6, n. 12, p. 391-413.

CAVALCANTE. Ian Andrade. "Pela Instrucção dos filhos do povo": Escolarização e cultura escolar na Salvador do pós-abolição, 1888-1906. Dissertação de Mestrado pelo Programa de Pós-graduação em Educação da Universidade Federal Fluminense, 2015.

CHALHOUB, Sidney. Cidade febril - Cortiços e epidemias na Corte Imperial. São Paulo, Companhia das Letras, 1996.

COLLING, Ana Maria. As primeiras médicas brasileiras - Mulheres à frente de seu tempo. FRONTEIRAS: Revista de História, v. 13, n. 24, p. 169-183.

DAMASCENO, Ana Daniella. Escolas Noturnas no Ceará: Ações de combate ao analfabetismo adulto na Primeira República. Dissertação de mestrado pelo Programa de Pós-graduação do Centro de Educação - Universidade Estadual do Ceará. Fortaleza, 2010, p. 81.

DICK, Sara Martha. As políticas públicas para o ensino secundário na Bahia: o liceu provincial. 1860-1890. Tese de doutorado pelo Programa de Pós-Graduação da Faculdade de Educação da Bahia - Universidade Federal de Bahia. Salvador, 2001.

FONSECA, Marcus Vinicius. A educação dos negros: uma nova face do processo de abolição da escravidão no Brasil. Bragança Paulista: Editora da Universidade São Francisco, 2002.

FONSECA, Marcus Vinicius; BARROS, Surya Aarovich Pombo de. (Org.). A História da Educação dos Negros no Brasil. Niteroi/RJ: EdUFF, 2016.

FORTUNA, Cristina Maria Mascarenhas. Sobre os afrodescendentes, abolicionismo, estudos sobre o negro e a Faculdade de Medicina (F.M.B.). Primaz do Brasil de 1808 a 1888. Faculdade de Medicina da Bahia. Salvador. Bahia, Brasil. p. 52.

GONDRA, José; SCHUELER, Alessandra. Educação, Poder e Sociedade no Império Brasileiro. São Paulo: Cortez, 2008;

JACOBINA, Ronaldo Ribeiro. Memória histórica do centenário da Faculdade de Medicina da Bahia (2008): os professores encantados, a visibilidade dos servidores e o 
protagonismo dos estudantes da FMB. Salvador: EDUFBA, Faculdade de Medicina, 2013.

JULIA, Dominique. A Cultura Escolar como Objeto História. Gizele de Souza (Tradução). Revista Brasileira de História de Educação. n. 1 jan./jun. 2001, p22. Disponível em: http://periodicos.uem.br/ojs/index.php/rbhe/article/view/38749. Acesso em 13 de abril de 2020.

KELLER, Evelyn Fox. Qual foi o impacto do feminismo na ciência. Cadernos Pagu, 2006, v. 27, n. 27, p. 32.

LAVIGNE. Os meus 87 anos outros assuntos. Salvador, Bahia. Editora Mensageiro da Paz. 1971, p.123.

LIMA, Déborah Kelman. O Banquete Espiritual da Instrução: o Ginásio da Bahia, Salvador: 1895-1942. Dissertação de Mestrado pelo Programa de Pós-Graduação em História Social, Universidade Federal da Bahia, 2003, p 24.

LOPES, Katia Geni Cordeiro. A presença de negros em espaços de instrução elementar da cidade-corte: O caso da Escola da Imperial Quinta da Boa Vista. Dissertação de mestrado, Programa de Pós-Graduação em Políticas Públicas, Universidade do Estado do Rio de Janeiro, 2012.

LUZ, Itacir Marques da. Compassos letrados: Profissionais negros entre instrução e ofício no Recife (1840-1860). Dissertação de mestrado - Programa de Pós-Graduação em Educação, UFPB, 2008.

MAC CORD, Marcelo. Artífices da cidadania: mutualismo, educação e trabalho no recife oitocentista. Campinas, SP: Ed Unicamp, 2012.

MAC CORD, Marcelo; ARAÚJO, Carlos Moreira de; GOMES, Flávio dos Santos (orgs). Rascunhos Cativos: educação, escolas e ensino no Brasil escravista. Rio de Janeiro: 7 Letras/Faperj, 2017.

MACHADO, Maria Helena Pereira Toledo; CASTILHO, Celso Thomas. Tornando-se livres: Agentes históricos e lutas sociais no processo de abolição. São Paulo: EDUSP, 2015.

MAGALHÃES, Justino. "Um contributo para a História do processo de escolarização da sociedade portuguesa na transição do Antigo Regime". In: Educação, Sociedade e Culturas, n 5. Porto: Afrontamento, 1996, p32.

MEIRELLES, Nevolanda Sampaio et al. Teses doutorais de titulados pela Faculdade de Medicina da Bahia, de 1840 a 1928. Gazeta Médica da Bahia, 2008, v. 74, n. 1, p 11.

OLIVEIRA, Eduardo José de. Da responsabilidade Médica. FAMEB: 102-O. Lista de Teses. Gazeta Médica. pg. 73. 2004.

PAIVA, Vanilda Pereira. Educação Popular e Educação de Adultos. $5^{\text {a }}$ edição. São Paulo: Edições Loyola - Ibrades, 1987. 
PERES, Eliane. Templo de Luz: Os Cursos noturnos masculinos de Instrução primária da Biblioteca Pública Pelotense 1875 - 1915. Pelotas, RS: Seiva publicações, 2001, p. 48.

RAGO, Elisabeth Juliska. A ruptura do mundo masculino da medicina: médicas brasileiras no século XIX. Cadernos, 2000. n. 15, p. 215.

REIS, Adriana Dantas. Cora: lições de comportamento feminino na Bahia do século XIX. Universidade Federal da Bahia, Centro de Estudos Baianos, 2000, pg. 65.

REIS, João José. Ganhadores: a greve negra de 1857 na Bahia. São Paulo: Companhia das letras, 2019.

SANTOS, Jucimar Cerqueira dos. Escolas noturnas para trabalhadores na Bahia (1870-1889). Dissertação de Mestrado pelo Programa de Pós-Graduação em História Social da Faculdade de Filosofia e Ciências Humanas, Universidade Federal da Bahia, Salvador, 2017.

SILVA, Fabiano Moreira da. Professorado municipal de Salvador: queixas, crises e greves (1912-1918). Dissertação de mestrado em História Social pelo Programa de PósGraduação da Universidade Federal da Bahia, 2017.

SILVA, José Carlos de Araújo. O Recôncavo baiano e suas escolas de primeiras letras. (1827-1852): Um estudo do cotidiano escolar. Dissertação de mestrado pelo Programa de Pós-Graduação em Educação da Faculdade de Educação da Universidade Federal da Bahia, Salvador, 1999, p36.

SILVA. Benedicto Alves de Castro. A cachoeirana Doutora Odília Teixeira Lavigne. Gente e memória. A Tarde. 2011, p6.

SOUSA, Ione Celeste Jesus de. Escolas ao Povo: experiências de escolarização de pobres na Bahia - 1870 a 1890. Tese de doutorado pelo Programa de Estudos Pós-Graduados em História / Pontifícia Universidade Católica de São Paulo: São Paulo, 2006, p. 202.

TRINDADE, Diamantino Fernandes; TRINDADE, Laís dos Santos Pinto. Os Pioneiros da Ciência Brasileira: Bartholomeu de Gusmão, José Bonifácio, Landell de Moura e D. Pedro II. Revista Sinergia, 2003, v. 4, p. 163-169.

VILLELA, Heloisa de Oliveira S. O mestre-escola e a professora. In: LOPES, Eliane Marta Teixeira; FARIA FILHO, Luciano Mendes; VEIGA, Cynthia Greive (org) 500 anos de educação no Brasil. Belo Horizonte: Autêntica, 2000. 